\title{
Atividade de enzimas fermentativas em raízes e nódulos de soja sob condições de hipóxia e pós-hipóxia
}

\author{
Fermentative enzymes activity in soybean roots and nodules under hypoxia and \\ post-hypoxia conditions
}

Junior Borella ${ }^{I^{*}}$ Marcel Angelo Durigon ${ }^{I}$ Luciano do Amarante ${ }^{I}$ Beatriz Marti Emygdio $^{I I}$

RESUMO

O objetivo deste trabalho foi avaliar a atividade de enzimas fermentativas em raizes e nódulos de soja (Glycine max) sob condições de hipóxia e pós-hipóxia. Os genótipos Fundacep 53 RR e BRS Macota foram cultivados em vasos de $3 L$ contendo vermiculita como substrato em associação com Bradyrhizobium elkanii em casa de vegetação. No estádio R2, o sistema radicular das plantas foi submetido à hipóxia pelo encaixe de um segundo vaso sem perfurações e inundado com solução nutritiva diluida a 1/3 da concentração original, por 8 dias. Posteriormente, foram retirados os vasos sem perfurações para avaliação da recuperação. O material vegetal foi coletado no $2^{\circ}, 4^{\circ}$, 60 e e $8^{\circ}$ dias após a inundação ou recuperação, juntamente com os controles para a dosagem da atividade das enzimas álcool desidrogenase $(A D H)$, piruvato descarboxilase (PDC) e lactato desidrogenase (LDH) em raizes e nódulos. Os dados foram submetidos à ANOVA e comparados pelo teste de Tukey a 5\% de probabilidade. As atividades da ADH, PDC e LDH foram fortemente estimuladas com a inundação, especialmente em nódulos, e diminuirram com a recuperação, em ambos os genótipos. Fundacep 53 RR respondeu de forma mais efetiva aos efeitos dos tratamentos.

Palavras-chave: Glycine max, alagamento, deficiência de oxigênio, metabolismo anaeróbico.

\section{ABSTRACT}

This study aimed to evaluate the activity of fermentative enzymes in soybean (Glycine max) roots and nodules under hypoxia and post-hypoxia conditions. The soybean genotypes Fundacep $53 R R$ and BRS Macota associated with Bradyrhizobium elkanii were grown in $3 L$ pots containing vermiculite as substrate under greenhouse conditions. Root system of plants at the R2 stage was subjected to hypoxia by blocking drainage of the pot, by fitting a second one without holes and flooded with nutrient solution diluted one-third of the original. The flooding of the plants was carried out for eight days and after, the pot without drilling was removed for recovery assessment. Non-waterlogged plants were kept as control. Activities of the fermentation enzymes alcohol dehydrogenase $(A D H)$, pyruvate decarboxylase $(P D C)$ and lactate dehydrogenase $(L D H)$ were quantified in roots and nodules collected at 2, 4, 6 and 8 days after flooding or recovery. Data were analyzed by ANOVA and compared by the Tukey test $(P \leq 0,05)$. Activities of ADH, PDC and LDH were hardly stimulated during flooding, especially in nodules, in both genotypes and decreased with recovery. Fundacep 53 RR responded more effectively to treatment effects.

Key words: Glycine max, waterlogging, oxygen deficiency, anaerobic metabolism.

\section{INTRODUÇÃO}

A respiração tem um papel crucial no metabolismo energético do carbono nos vegetais, pois fornece a maior parte da energia celular (VAN DONGEN et al., 2011). A inundação impede as trocas gasosas entre o sistema radicular e o espaço poroso do solo (ZABALZA et al., 2009), afetando fortemente o metabolismo da planta (BAILEYSERRES \& VOESENEK, 2008). Uma das consequências imediatas da depleção de oxigênio é a ativação do metabolismo anaeróbico e uma redução significativa na produção de energia, de 36 moléculas de ATP para duas moléculas de ATP por molécula de glicose via glicólise (KUMUTHA et al., 2008; SAIRAM et al., 2009). A sobrevivência das plantas passa a depender exclusivamente do

\footnotetext{
'Universidade Federal de Pelotas (UFPel), Campus Universitário S/N, 96160-000, Capão do Leão, RS, Brasil. E-mail: borellaj@gmail.com.

*Autor para correspondência.

"Empresa Brasileira de Pesquisa Agropecuária (Embrapa), Embrapa Clima Temperado, Pelotas, RS, Brasil.
} 
metabolismo anaeróbico. Essas mudanças atuam como sinal para posteriores respostas adaptativas, entre elas, mudanças morfológicas e anatômicas, como a formação de aerênquima, raízes adventícias (YIN et al., 2010) e alongamento do caule (FUKAO \& BAILEY-SERRES, 2004), importantes para a otimização do status de energia (VAN DONGEN et al., 2011).

Sob hipóxia, a síntese de muitas proteínas da célula é suprimida, enquanto que a síntese de um grupo específico de proteínas aumenta. Entre elas, estão enzimas de duas vias importantes, a primeira utiliza o piruvato como substrato para produzir lactato através da lactato desidrogenase (LDH) e a segunda via produz etanol através de duas reações subsequentes, catalisadas pela piruvato descarboxilase (PDC) e álcool desidrogenase (ADH) (SHINGAKI-WELLS et al., 2011). No entanto, lactato é tóxico e etanol se difunde rapidamente para fora das células, levando a uma perda considerável de carbono durante a hipóxia (ROCHA et al., 2010). Em contrapartida, regeneram $\mathrm{NAD}^{+}$, que é essencial para manter o fluxo glicolítico e remover o excesso de prótons (ARMSTRONG et al., 2009).

A soja, além de apresentar importância conômica mundial, quando associada simbioticamente com rizóbio, contribui para a entrada de $\mathrm{N}$ no ambiente, com evidentes vantagens para a agricultura sustentável. Originária de áreas alagadiças do norte da China, apresenta variabilidade genética para tolerar o excesso de umidade no solo (THOMAS et al., 2000). Muitos estudos têm sido realizados para elucidar os efeitos do déficit de oxigênio em plantas, no entanto poucos trabalhos são relacionados com plantas noduladas, especialmente em soja. Nesse contexto, o objetivo deste trabalho foi caracterizar a atividade de enzimas da fermentação láctica e alcoólica em raízes e nódulos de dois genótipos de soja em diferentes períodos de hipóxia e pós-hipóxia.

\section{MATERIAL E MÉTODOS}

O experimento foi conduzido em casa de vegetação da Universidade Federal de Pelotas (UFPel). Sementes de soja (Glycine max L. Merril) de dois cultivares, 'Fundacep 53 RR' e 'BRS Macota', de ciclo precoce, foram semeadas em vasos de polietileno furados, de três litros, contendo vermiculita média expandida lavada como substrato. No estádio V0 (FEHR et al., 1971), foi realizado o desbaste, permanecendo três plântulas/vaso e realizada a inoculação com Bradyrhizobium elkanii, estirpe SEMIA 587 (FEPAGRO). As plantas foram nutridas duas vezes por semana com solução de HOAGLAND \& ARNON (1938) sem nitrogênio mineral, na proporção de $250 \mathrm{~mL}$ vaso $^{-1}$. No estádio R2 (FEHR et al., 1971), o sistema radicular foi submetido à inundação pelo encaixe de um segundo vaso de mesmo modelo e sem perfurações e inundado com solução nutritiva diluída a $1 / 3$ da concentração original, mantendo-se uma lâmina de $20 \mathrm{~mm}$ sobre o substrato. $\mathrm{O}$ teor de $\mathrm{O}_{2}$ na solução foi monitorado diariamente com o auxílio de um oxímetro (Handylab OX1). A inundação das plantas foi conduzida por oito dias. Após esse período, as plantas destinadas à avaliação da recuperação tiveram os vasos sem perfurações retirados para a drenagem da solução. As

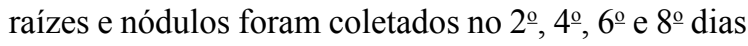
após a inundação ou recuperação, juntamente com seus respectivos controles e armazenados a $-80^{\circ} \mathrm{C}$, para a dosagem da atividade das enzimas fermentativas.

As amostras foram maceradas em gral com $\mathrm{N}_{2}$ líquido, contendo polivinilpolipirrolidona (PVPP) 5\%, seguido de homogeneização em tampão Tris-HCl 50mM (pH 7,5) contendo ditiotreitol (DTT) $1 \mathrm{mM}$. O extrato homogeneizado foi centrifugado a $12.000 \mathrm{~g}$ por $20 \mathrm{~min}$ a $4^{\circ} \mathrm{C}$. Uma alíquota de $2,5 \mathrm{~mL}$ do sobrenadante foi dessalinizada em coluna de cromatografia de exclusão molecularPD10-Sephadex G-25M (GE Healthcare, Buckinghamshire, UK). A fração proteica eluída foi utilizada para determinar a atividade enzimática da álcool desidrogenase (ADH - EC 1.1.1.1), piruvato descarboxilase (PDC EC 4.1.1.17) e da lactato desidrogenase (LDH - EC 1.1.1.17). A atividade enzimática foi determinada em espectrofotômetro pelo monitoramento da oxidação do $\mathrm{NADH}$ a $340 \mathrm{~nm}$ por $2 \mathrm{~min}$ a $30^{\circ} \mathrm{C}$, em cubeta de polimetilmetacrilato, em meio de reação de $1,5 \mathrm{~mL}$.

A atividade da $\mathrm{ADH}$ foi monitorada no sentido da formação do etanol (acetaldeído $\rightarrow$ ADH $\rightarrow$ etanol) em meio de reação contendo tampão Tris$\mathrm{HCl} 50 \mathrm{mM}$, pH 7,5 para nódulo e fosfato de potássio, pH 7,0 para raízes, NADH 0,2mM, acetaldeído $5 \mathrm{mM}$ e extrato enzimático (HANSON et al., 1984). A atividade da PDC foi monitorada no sentido de formação do etanol em uma reação acoplada (piruvato $\rightarrow$ PDC $\rightarrow$ acetaldeído $\rightarrow$ ADH $\rightarrow$ etanol) em meio de reação contendo tampão MES $50 \mathrm{mM}$ (nódulo: $\mathrm{pH}$ 6,0; raiz: $\mathrm{pH} 6,5$ ), NADH 0,2mM, tiamina pirofosfato $0,5 \mathrm{mM}$, cloreto de magnésio $1 \mathrm{mM}$, ácido oxâmico 20mM, ADH 10U, piruvato de sódio $10 \mathrm{mM}$ e extrato enzimático (HANSON et al., 1984). A atividade da LDH foi monitorada no sentido de formação do lactato (piruvato $\rightarrow \mathrm{LDH} \rightarrow$ lactato) em meio de reação contendo tampão Tris- $\mathrm{HCl} 50 \mathrm{mM}$, pH 7,5 para nódulo e fosfato de potássio, $\mathrm{pH}$ 7,0 para

Ciência Rural, v.43, n.6, jun, 2013. 
raízes, NADH $0,2 \mathrm{mM}$, cianeto de potássio $3 \mu \mathrm{M}$, metilpirazol $4 \mathrm{mM}$, piruvato de sódio $10 \mathrm{mM}$ e extrato enzimático (HANSON \& JACOBSEN 1984).

O delineamento experimental adotado foi inteiramente casualizado em esquema fatorial $2 \times 4 \times 2$ (regime hídrico $\mathrm{x}$ período de inundação ou recuperação x genótipos) com três repetições. Cada repetição consistiu em um vaso com três plantas. Os dados foram submetidos à análise de variância (ANOVA) e, em caso de significância pelo teste $\mathrm{F}$, as médias foram comparadas pelo teste de Tukey a $5 \%$ de probabilidade, pelo programa estatístico SAS 8.0 (SAS Institute Inc. Cary, NC, USA).

\section{RESULTADOS}

Os valores de $\mathrm{O}_{2}$ monitorados na solução nutritiva caíram de $6,5 \mathrm{mg} \mathrm{L}^{-1}$, sob condições de normóxia, para $1,5 \mathrm{mg} \mathrm{L}^{-1}$ no primeiro dia de inundação, chegando aos níveis de $0,5 \mathrm{mg} \mathrm{L}^{-1}$ no quarto dia de inundação e $0,35 \mathrm{mg} \mathrm{L}^{-1}$ no oitavo dia, caracterizando a hipóxia no sistema de cultivo (dados não mostrados). A atividade da álcool desidrogenase (ADH) em raízes sob hipóxia aumentou ao longo do período de inundação, sendo fortemente ativa aos 6 e 8 dias de inundação para ambos os genótipos (Figura $1 \mathrm{~A}$ e B). Com o retorno à normóxia, os níveis de atividade da $\mathrm{ADH}$ caíram consideravelmente já no $2^{\circ}$ dia de recuperação, em relação à atividade do $8^{\circ}$ dia de inundação, atingindo os níveis do controle no $6^{\circ}$ dia de recuperação para BRS Macota (Figura 1C e D).

Em nódulos, a hipóxia estimulou o rápido aumento da atividade da $\mathrm{ADH}$ ao longo do período de inundação e em relação ao controle. Observa-se que a ADH foi fortemente ativa aos quatro dias de inundação para o genótipo Fundacep 53 RR (Figura $1 \mathrm{E})$, enquanto que, para BRS Macota, o aumento considerável de atividade ocorreu aos oito dias (Figura $1 \mathrm{G})$. Ambos os genótipos responderam à recuperação, com queda dos níveis de atividade da $\mathrm{ADH}$ no decorrer do tempo. Em Fundacep 53 RR, o período de oito dias foi suficiente para a atividade da ADH decrescer aos níveis pré-hipóxicos (Figura 1F e $\mathrm{H}$ ).

A atividade da PDC em raízes sob hipóxia aumentou significativamente e de forma proporcional ao tempo de estresse em ambos os genótipos (Figura 2A e C). Aos dois dias de recuperação, diminuiu consideravelmente, resultando em valores de atividade semelhantes aos dois dias de inundação, atingindo os níveis do controle em BRS Macota (Figura 2 B e D). Em nódulos, o aumento da atividade da PDC para Fundacep 53 RR, em relação ao controle, foi significativo desde os dois dias de inundação, aumentando com o período de hipóxia e estabilizando-se aos 6 e 8 dias de tratamento. Em BRS Macota, a atividade diferiu do controle apenas aos 6 dias de inundação, sendo consideravelmente elevada aos oito dias (Figura 2E e G). Com a recuperação, a atividade da PDC para Fundacep 53RR não retornou aos níveis do controle, apesar de diminuir com o período de recuperação, enquanto que, em BRS Macota, a atividade decresceu aos níveis préhipóxicos aos 8 dias de recuperação (Figura $2 \mathrm{~F}$ e H).

Em raízes de Fundacep 53RR sob dois dias de inundação, a atividade da LDH aumentou significativamente em relação ao controle, efeito intensificado com o tempo de tratamento hipóxico, atingindo valores máximos e equivalentes entre o $6^{\circ}$ e 8o dias de hipóxia. Em BRS Macota, a atividade da enzima foi superior ao controle aos quatro dias de inundação, aumentando fortemente nos tempos posteriores de estresse, porém atingindo valores inferiores ao de Fundacep 53RR (Figura 3A e C). O retorno da atividade aos níveis pré-hipóxicos ocorreu aos quatro dias de recuperação para Fundacep 53RR, apesar de extremamente baixos aos dois dias de normóxia e, em BRS Macota, aos dois dias de normóxia (Figuras 3B e D).

A atividade da LDH em nódulos de Fundacep 53RR foi superior ao controle aos dois dias de inundação, mantendo-se semelhante ao longo dos períodos de tratamento. Em BRS Macota foi verificado um aumento aos quatro dias de inundação (Figura 3E e G). Com o retorno à normóxia, a atividade retornou aos níveis semelhantes ao controle no genótipo Fundacep 53RR aos seis dias de recuperação, enquanto que, em BRS Macota, a atividade foi restabelecida aos níveis pré-hipóxicos apenas no oitavo dia de recuperação (Figura $3 \mathrm{~F} \mathrm{e} \mathrm{H}$ ).

\section{DISCUSSÃO}

Embora os níveis de $\mathrm{O}_{2}$ não tenham se exaurido completamente na solução nutritiva ao longo do período de oito dias, a quantidade que pode ser aproveitada pelas raízes é muito pequena, pois os teores de $\mathrm{O}_{2}$ decresceram a níveis mínimos e a sua taxa de difusão em água é $10^{4}$ vezes menor do que no ar (ARMSTRONG et al., 2009). O rendimento de energia produzido sob hipóxia é de apenas duas moléculas de ATP por molécula de glicose via glicólise, em detrimento de 36 moléculas de ATP produzidas pela fosforilação oxidativa em normóxia (ZABALZA et al., 2009). O acúmulo de NADH e a concomitante depleção de $\mathrm{NAD}^{+}$disponível levaria a uma inibição da glicólise, que é impedida 


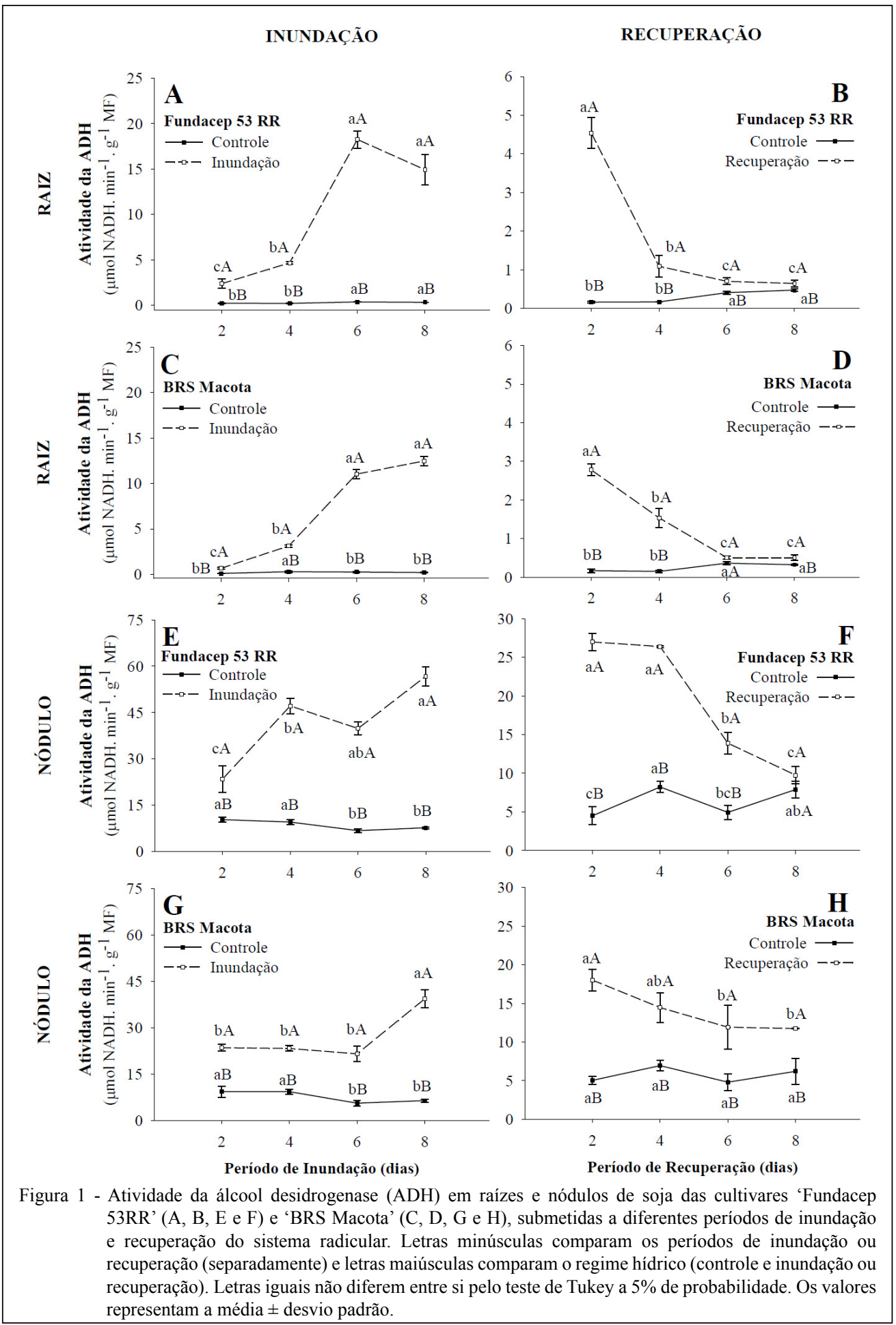

pela oxidação do NADH por meio da atividade das enzimas fermentativas (BAILEY-SERRES \& VOESENEK, 2008).

O baixo nível de oxigênio causa rápidas mudanças na transcrição de genes, síntese e degradação de proteínas e no metabolismo celular em Arabidopsis thaliana (BAILEY-SERRES \& VOESENEK, 2008). Aumento rápido da atividade da enzima $\mathrm{ADH}$, tanto em raízes quanto em nódulos dos genótipos de soja Fundacep 53RR e BRS Macota,

Ciência Rural, v.43, n.6, jun, 2013. 


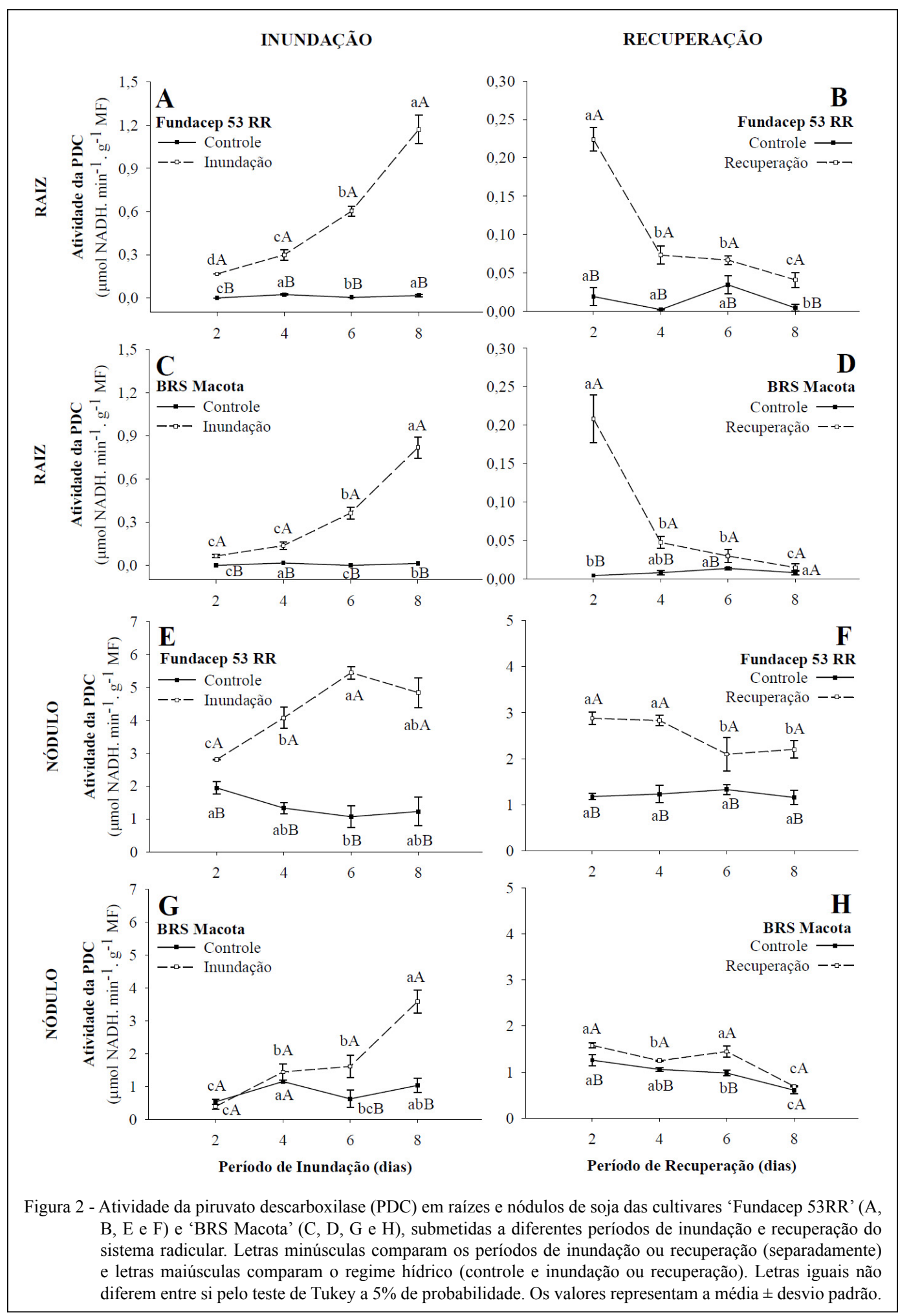

sob condições de hipóxia, está relacionado à rápida expressão do gene $a d h$, gene chave envolvido na fermentação (CHRISTIANSON et al., 2010).
$\mathrm{O}$ aumento da expressão dos genes e atividade das enzimas ADH e PDC é essencial para a tolerância à hipóxia (CHRISTIANSON et 
al., 2010). Pode ser observado, nas figuras 1 e 2, comportamento semelhante de atividade para $\mathrm{ADH}$ e PDC, enzimas da rota responsável pela produção do etanol. O etanol é provavelmente o maior produto da fermentação em tecidos de plantas superiores e sua rota é responsável pela tolerância ao déficit de

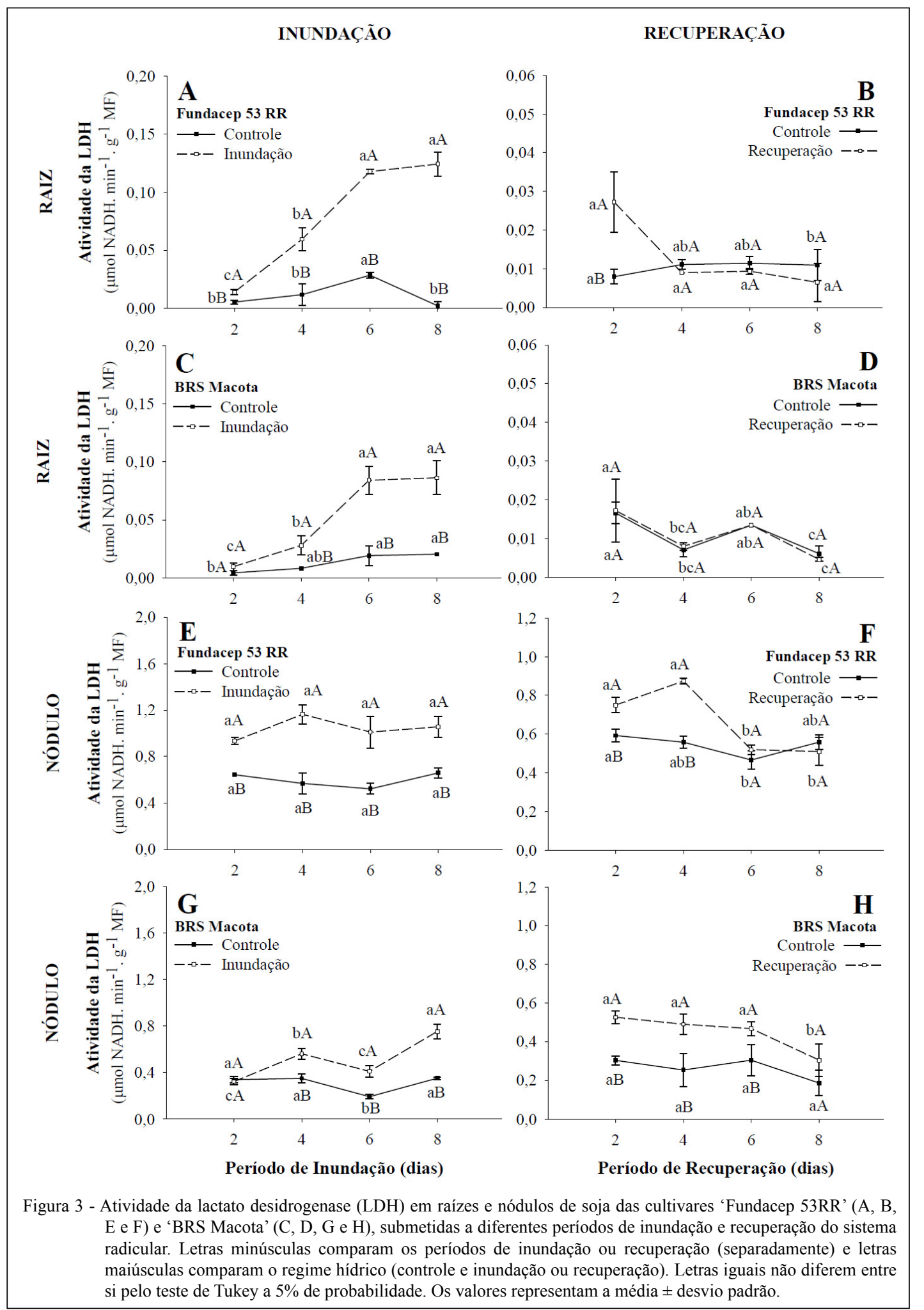

Ciência Rural, v.43, n.6, jun, 2013. 
$\mathrm{O}_{2}$, produzido sequencialmente pela acão da PDC, através da oxidação e descarboxilação do piruvato em acetaldeído, que é substrato para ADH produzir etanol (ZABALZA et al., 2009). Em termos de eficiência, a rota de formação do etanol é mais importante que a rota de formação de lactato, pois essa rota promove maior geração de $\mathrm{NAD}^{+}$e o consumo de prótons, além de não produzir compostos tóxicos (SAIRAM et al., 2009). Em ambos os genótipos, a fermentação alcoólica constituiu a rota preferencial de produção de energia sob deficiência de $\mathrm{O}_{2}$, tanto em raízes quanto em nódulos, visto que nesses órgãos as atividades das enzimas ADH e PDC foram superiores em relação à $\mathrm{LDH}$ ao longo do tratamento hipóxico.

A enzima LDH é induzida sob hipóxia e seu produto, lactato, é muitas vezes produzido antes do etanol, logo que a planta entra em hipóxia, acidificando o citosol. A queda do $\mathrm{pH}$ citosólico sinaliza para a produção de etanol e ativa a PDC e a ADH é ativada sob condições de hipóxia (GOOD \& CROSBY, 1989). O aumento da atividade da LDH foi observado aos dois dias de inundação para Fundacep 53RR, em raízes e nódulos, e, para BRS Macota, aos quatro dias de inundação, demonstrando que Fundacep 53RR é mais eficiente em responder ao déficit de $\mathrm{O}_{2}$, alterando o metabolismo como mecanismo de sobrevivência. A rápida percepção e mudança da fermentação láctica para a alcoólica representa um importante indicador da capacidade dos genótipos de soja sobreviverem à hipóxia sem sofrer danos celulares extensivos (ZABALZA et al., 2009). Além disso, as plantas que apresentam a capacidade de reprimir o metabolismo anaeróbico, retornando a atividade das enzimas fermentativas aos níveis préhipóxicos rapidamente durante a recuperação do estresse, apresentam maior tolerância ao déficit de $\mathrm{O}_{2}$, como observado nos resultados obtidos para ambos os genótipos.

Com o retorno à normóxia, embora ambos os genótipos responderam com queda da atividade das enzimas, Fundacep 53RR demonstrou maior eficiência em reduzir a atividade aos níveis do controle, considerando os níveis mais elevados de atividade durante a hipóxia em relação a BRS Macota. Isso demonstra que Fundacep 53RR apresentou maior capacidade de restabelecer e readaptar o metabolismo frente à inundação e o declínio rápido da atividade da $\mathrm{ADH}$, repercutindo em diminuição dos teores de etanol, que, sendo volátil, representa economia na perda de carbono (ROCHA et al., 2010). Embora a indução da atividade da ADH, PDC e LDH possam contribuir para a sobrevivência e superar a escassez de energia através da fermentação de carboidratos para manter a produção de ATP sob hipóxia, o benefício sob tais condições vai depender do tipo de tecido, estágio de desenvolvimento, espécie, genótipo, da gravidade e duração do estresse (FUKAO \& BAILEY-SERRES, 2004).

\section{CONCLUSÃO}

Em raízes e nódulos de soja, a hipóxia causa um aumento abrupto na atividade das enzimas fermentativas. A obtenção de energia nessa condição ocorre principalmente pela fermentação alcoólica, considerando as atividades mais elevadas da PDC e $\mathrm{ADH}$ em relação à $\mathrm{LDH}$ nesses órgãos. $\mathrm{Na}$ condição de pós-hipóxia, o efeito é inverso, ocorrendo decréscimo considerável da atividade dessas enzimas. Esses efeitos são mais pronunciados no genótipo Fundacep 53RR.

\section{AGRADECIMENTOS}

Ao convenio EMBRAPA/Monsanto, pela ajuda financeira, à Fundação Estadual de Pesquisa Agropecuária (FEPAGRO), pela estirpe Bradyrhizobium elkanii, e à Coordenação de Aperfeiçoamento de Pessoal de Nível Superior (CAPES), pela concessão da bolsa de Mestrado ao primeiro autor.

\section{REFERÊNCIAS}

ARMSTRONG, W. et al. Measuring and interpreting respiratory critical oxygen pressures in roots. Annals of Botany, v.103, p.281-293, 2009. Disponível em: <http://aob.oxfordjournals.org/ content/103/2/281>. Acesso em: 28 set. 2011. doi: 10.1111/j.14698137.2009.02907.x.

BAILEY-SERRES, J.; VOESENEK, L.A.C.J. Flooding stress: acclimations and genetic diversity. Annual Review Plant Biology, v.59, p.313-339, 2008. Disponível em: $<$ http://www.annualreviews. org/doi/abs/10.1146/annurev.arplant.59.032607.092752>. Acesso em: 28 set. 2011. doi: 10.1146/annurev.arplant.59.032607.092752.

CHRISTIANSON, J.A. et al. Global gene expression responses to waterlogging in roots and leaves of cotton (Gossypium hirsutum L.). Plant Cell Physiology, v.51, p.21-37, 2010. Disponível em: $<$ http://pcp.oxfordjournals.org/content/51/1/21.full.pdf+html $>$. Acesso em: 12 ago. 2011. doi: 10.1093/pcp/pcp163.

FEHR, W.R. et al. Stage of development descriptions for soybeans, Glycine max (L.) Merril. Crop Science, v.11, p.929-931, 1971.

FUKAO, T.; BAILEY-SERRES, J. Plant responses to hypoxia. Is survival a balancing act? Trends Plant Science, v.9, p.1403-1409, 2004. Disponível em: <http://www.sciencedirect.com/science/ article/pii/S1360138504001761>. Acesso em: 16 jun. 2011. doi: 10.1016/j.tplants.2004.07.005.

GOOD, A.G.; CROSBY, W.L. Anaerobic induction of alanina aminotransferase in barley root tissue. Plant Physiology, v.90, p.1305-1309, 1989. 
HANSON, A.D.; JACOBSEN, J.V. Control of Lactate dehydrogenase, lactate glycolysis, and a-amilase by $\mathrm{O}_{2}$ deficit in barley aleurone layers. Plant Physiology, v.74, p.566-572, 1984.

HANSON, A.D. et al. Regulated expression of three alcohol dehydrogenase genes in barley aleurone layers. Plant Physiology, v.75, p.573-581, 1984 .

HOAGLAND, D.R.; ARNON, D.I. The water culture method of growing plants without soil. California Agricultural Experimental Station, n.347, p.1-39, 1938.

KUMUTHA, D. et al. Effect of waterlogging on carbohydrate metabolism in pigeon pea (Cajanus cajan L.): Upregulation of sucrose synthase and alcohol dehydrogenase. Plant Science, v. 175, p.706-716, 2008. Disponível em: $<\mathrm{http}$ ://www.sciencedirect.com/ science/article/pii/S0168945208002100>. Acesso em: 16 jun. 2011. doi: 10.1016/j.plantsci.2008.07.013.

ROCHA, M. et al. Glycolysis and the tricarboxylic acid cycle are linked by alanine aminotransferase during hypoxia induced by waterlogging of Lotus japonicus. Plant Physiology, v.152, p.1501-1513, 2010. Disponível em: <http://www.plantphysiol. org/content/152/3/1501.short>. Acesso em: 12 set. 2011 . doi: $10.1104 /$ pp.109.150045.

SAIRAM, R.K. et al. Waterlogging-induced increase in sugar mobilization, fermentation, and related gene expression in the roots of mung bean (Vigna radiata). Journal of Plant Physiology, v.166, p.602-616, 2009. Disponível em: <http://
www.sciencedirect.com/science/article/pii/S0176161708002757>. Acesso em: 12 set. 2011. doi: 10.1016/j.jplph.2008.09.005.

SHINGAKI-WELLS, R.N. et al. Differential molecular responses of rice and wheat coleoptiles to anoxia reveal novel metabolic adaptations in amino acid metabolism for tissue tolerance. Plant Physiology, v.156, p.1706-1724, 2011. Disponível em: <http:// www.plantphysiol.org/content/early/2011/05/27/pp.111.175570>. Acesso em: 12 set. 2011. doi: 10.1104/pp.111.175570.

THOMAS, A.L. et al. Rendimento de grãos de cultivares de soja na várzea. Pesquisa Agropecuária gaúcha, v.6, p.1294-1301, 2000 .

VAN DONGEN, J.T. et al. Regulation of respiration in plants: a role for alternative metabolic pathways. Journal of Plant Physiology, v.168, p.1434-1443, 2011. Disponível em: <http:// www.sciencedirect.com/science/article/pii/S0176161710004931>. Acesso em: 12 set. 2011. doi: 10.1016/j.jplph.2010.11.004.

YIN, D. et al. Morpho-anatomical and physiological responses of two Dendranthema species to waterlogging. Environmental and Experimental Botany, v.68, p.122-130,2010. Disponível em: $<$ http:// www.sciencedirect.com/science/article/pii/S0098847209002494>. Acesso em: 15 set. 2011. doi: 10.1016/j.envexpbot.2009.11.008.

ZABALZA, A. et al. Regulation of respiration and fermentation to control the plant internal oxygen concentration. Plant Physiology, v.149, p.1087-1098, 2009. Disponível em: <http://www. plantphysiol.org/content/149/2/1087.full.pdf + html>. Acesso em: 12 set. 2011. doi: 10.1104/pp.108.129288.

Ciência Rural, v.43, n.6, jun, 2013. 